\title{
Article
}

\section{The Prevalence and Predictors of Hypertension and the Metabolic Syndrome in Police Personnel}

\author{
James D. Yates ${ }^{1, *}$, Jeffrey W. F. Aldous ${ }^{1}{ }^{\complement}$, Daniel P. Bailey ${ }^{1,2,3}{ }^{\oplus}$, Angel M. Chater ${ }^{1} \mathbb{D}$, Andrew C. S. Mitchell ${ }^{1}$ \\ and Joanna C. Richards $1, *$ D \\ 1 Institute for Sport and Physical Activity Research, University of Bedfordshire, Bedford MK41 9EA, UK; \\ jeffrey.aldous@beds.ac.uk (J.W.F.A.); daniel.bailey@brunel.ac.uk (D.P.B.); angel.chater@beds.ac.uk (A.M.C.); \\ andrew.mitchell@beds.ac.uk (A.C.S.M.) \\ 2 Sedentary Behaviour, Health and Disease Research Group, Brunel University London, \\ Uxbridge UB8 3PH, UK \\ 3 Division of Sport, Health and Exercise Sciences, Department of Life Sciences, Brunel University London, \\ Uxbridge UB8 3PH, UK \\ * Correspondence: james.yates8@btinternet.com (J.D.Y.); jo.richards@beds.ac.uk (J.C.R.)
}

check for updates

Citation: Yates, J.D.; Aldous, J.W.F.; Bailey, D.P.; Chater, A.M.; Mitchell, A.C.S.; Richards, J.C. The Prevalence and Predictors of Hypertension and the Metabolic Syndrome in Police Personnel. Int. J. Environ. Res. Public Health 2021, 18, 6728. https:// doi.org/10.3390/ijerph18136728

Academic Editors: Raquel Alarcón and Maria del Mar Requena Mullor

Received: 5 May 2021

Accepted: 16 June 2021

Published: 22 June 2021

Publisher's Note: MDPI stays neutral with regard to jurisdictional claims in published maps and institutional affiliations.

Copyright: (c) 2021 by the authors. Licensee MDPI, Basel, Switzerland. This article is an open access article distributed under the terms and conditions of the Creative Commons Attribution (CC BY) license (https:// creativecommons.org/licenses/by/ $4.0 /)$

\begin{abstract}
Hypertension and metabolic syndrome (METSYN) are reportedly high in police forces. This may contribute to health deterioration and absenteeism in police personnel. Police forces comprise of staff in 'operational' and 'non-operational' job types but it is not known if job type is associated to hypertension and METSYN prevalence. This study aimed to explore the prevalence of hypertension and METSYN, the factors associated with the risk of hypertension and METSYN, and compare physiological, psychological, and behavioural factors between operational and non-operational police personnel. Cross-sectional data was collected from 77 operational and 60 non-operational police workers. Hypertension and METSYN were prevalent in $60.5 \%$ and $20 \%$ of operational and $60.0 \%$ and $13.6 \%$ of non-operational police personnel, respectively $(p>0.05)$. Operational job type, moderate organisational stress (compared with low stress) and lower high-density lipoprotein cholesterol were associated with lower odds of hypertension, whereas increasing body mass index was associated with increased odds of hypertension $(p<0.05)$. None of the independent variables were significantly associated with the odds of METSYN. Operational police had several increased cardiometabolic risk markers compared with non-operational police. Given the high prevalence of hypertension and METSYN in operational and non-operational personnel, occupational health interventions are needed for the police and could be informed by the findings of this study.
\end{abstract}

Keywords: hypertension; metabolic syndrome; stress; sitting time; police

\section{Introduction}

The number of employees in the English and Welsh police forces is currently $7 \%$ lower than in 2010 [1]. With less police officers available for tasks, this may impact on the health and wellbeing of police personnel, increasing job demands and strain, potentially leading to increased sickness absence [2]. Absenteeism is a major problem in the police workforce in England and Wales with 58\% of staff reporting one or more days of sickness absence over a 12-month period [3].

A territory police organisation employs personnel in 'non-operational' and 'operational' job types to effectively serve a community [4]. Operational personnel are required to urgently and dynamically mobilise in response to unpredictable frontline incidents [5]. These personnel have an increased risk of cardiovascular events than the general population due to high levels of cardiometabolic risk markers [5] and sudden unpredictable bursts of strenuous activity [5]. Low physical activity levels, poor diet, and shift work may also contribute to increased cardiovascular risk in these personnel [6]. The presence of hypertension and metabolic syndrome (METSYN), which is a clustering of cardiometabolic risk markers, 
are highly prevalent in the police [7] and are significant predictors of cardiovascular events in this population [5].

Non-operational personnel work involves being sedentary while completing administrative and desk-based duties in an office environment [4]. High volumes of sedentary behaviour are associated with hypertension [7] and METSYN in the general population [8] and may therefore contribute to increased cardiovascular risk in non-operational personnel [9]. The prevalence of hypertension and METSYN, and differences in physiological, psychological and behavioural factors associated with cardiometabolic disease risk, has not been compared between operational and non-operational police personnel. It is also not known which physiological, psychological, and behavioural factors are associated with the presence of hypertension and METSYN in this occupational group. Research is needed in these areas to help identify if interventions need to be targeted to specific job types in the police and to identify the physiological, psychological, and behavioural factors that should be considered to reduce the risk of hypertension and METSYN.

The aims of this study were to (a) explore the prevalence of hypertension and METSYN in operational and non-operational police personnel, (b) compare physiological, psychological, and behavioural factors associated with cardiometabolic disease risk between operational and non-operational police personnel, and (c) investigate the association of physiological, psychological, behavioural, occupational, and demographic factors with the presence of hypertension and METSYN in the police.

\section{Materials and Methods}

\subsection{Study Overview}

This study had a cross-sectional design. Participants provided informed consent before data collection. The sample was divided into 'operational' $(n=77)$ and 'non-operational' $(n=60)$ roles. Operational personnel comprised of ranked police officers and personnel completing 'policing' tasks necessary in crime prevention and law enforcement such as scenes of crimes officers, investigation officers, and detention officers [10]. These roles involve large amounts of desk work but also involve mobilising to perform duties and activities that occur outside of the office environment [11]. Non-operational personnel support the organisation in largely administrative capacities [4] and are inclusive of control room, finance, human resources and communication officers, and are exclusively based in office environments.

\subsection{Participants and Recruitment}

A sample of 137 police officers and police staff, representing approximately $6 \%$ of the territory police organisation, were recruited via self-selection from two sites in a single territory police organisation in South East England. Recruitment was via site visits, presentations to the workforce, invitation emails from the Police and Crime Commissioner's office, and adverts on the organisation's intranet. Participants could be any individual employed by the police organisation free from significant injury or other contraindications to performing the tests for the study.

\subsection{Testing Protocol and Classifications}

\subsubsection{Online Survey}

Participants initially completed online questionnaires in private to collect demographic information (occupation, length of service, age, and gender); medical history and medication use (blood pressure and cholesterol medication) using non-validated items; behavioural questionnaires including a validated domain specific sitting time questionnaire [12] to measure total daily sitting time and workplace sitting time per day (intraclass correlation coefficients of 0.62-0.86); the validated short form International Physical Activity Questionnaire (IPAQ) (Spearman's $p$ clustered around 0.3 ) to classify those as low, moderate, or highly active [13]; self-reported smoking status (non-smoker, daily smoker or smoking less than daily) using non-validated items; the validated Alcohol Use Disorder 
Identification Test-Consumption Questions (AUDIT-C) (AUDIT and it's versions exhibit Cronbach's Alpha coefficients between 0.83 and 0.94) [14]; self-reported average hours of sleep per night using a non-validated item. Participants also completed questionnaires assessing psychological variables: the validated Police Organisational Stress (PSQ-ORG) and Police Operational Stress (PSQ-OP) questionnaires (Cronbach's Alpha > 0.8) [15] to classify those with low, moderate, or high stress [16]. These questionnaires were completed using Qualtrics (Qualtrics, Inc., London, UK).

\subsubsection{Physical Data Collection Session}

Following completion of online questionnaires, participants were required to either watch a familiarisation video of tests prior to their data collection session or complete the familiarisation in person at their worksite approximately two months prior to data collection. Participants were instructed to attend the data collection session having fasted for $\geq 9 \mathrm{~h}$, hydrated, and having avoided caffeine intake and strenuous exercise on the day of the data collection session. Tests were completed in the order described below.

\section{Blood Biomarkers}

Finger prick capillary blood sampling was used to collect $40 \mu \mathrm{L}$ of whole blood for analysis of total cholesterol (TC), high-density lipoprotein cholesterol (HDL-C), triglycerides, TC:HDL ratio, and blood glucose. Blood was analysed using the Cholestech LDX Analyzer (Cholestech Corp., Hayward, NJ, USA).

\section{Blood Pressure}

An Omron, M5-I automatic blood pressure monitor (Omron Matsusaka Co Ltd., Matsusaka, Japan) was used to measure resting systolic (SBP) and diastolic (DBP) blood pressure. Participants were seated and rested for 5 minutes prior to the measurement being taken on the left arm. Two measurements were taken with 30 seconds rest between readings. The average of the two readings was recorded.

\section{Anthropometry and Body Composition}

For anthropometry and body composition measurements, participants removed footwear and personal artefacts. Body mass and body fat \% were measured using a bioelectrical impedance analysis device (Tanita BC41MA Segmental Body Composition Analyzer; Tanita Corp., Tokyo, Japan) whilst wearing minimal clothing (shorts and t-shirt). Body mass index (BMI) was calculated as mass $(\mathrm{kg}) / \mathrm{height}\left(\mathrm{m}^{2}\right)$. Waist circumference (WC) was measured at the mid-point between the lower border of the ribs and the top of the iliac crest [17] using an adjustable tape measure (HaB Direct, Southam, UK). Hip circumference was measured at the widest part of the buttocks [17]. Waist-to-hip ratio was calculated as waist $(\mathrm{cm}) / \mathrm{hip}(\mathrm{cm})$ circumference.

\section{Lung Function}

An electronic MicroPlus spirometer (Carefusion, San Diego, CA, USA) was used to measure Forced Vital Capacity (FVC), Forced Expiratory Volume in one second $\left(\mathrm{FEV}_{1}\right)$ and $\mathrm{FEV}_{1}: \mathrm{FVC}$ ratio. Each participant was asked to inspire fully, then exhale as hard and as fast as possible into the microspirometer and keep going for as long as possible. A minimum of three attempts were performed with an acceptability criteria being when there was a $\leq 0.150 \mathrm{~L}$ differences between the largest and next largest FVC and FEV measurements [18].

\section{Handgrip Strength}

Handgrip strength was measured following the American Society of Hand Therapists protocol [19]. Participants were seated with shoulders adducted and neutrally rotated. The participant was asked to position the forearm in neutral position with the wrist positioned between $0^{\circ}$ and $30^{\circ}$ dorsiflexion. The participant gripped the Takei 5401 dynamometer 
(Takei Scientific Instruments Co., Ltd, Yashorida, Japan) maintaining a maximal isometric contraction of the fingers for three seconds [20]. Three tests were performed on the right (GRIPR) and left (GRIPL) hands with one minute rest between attempts. The highest score for each hand was recorded.

\section{Aerobic Fitness}

The Chester Step Test was conducted according to published protocols [21] using a pre-recorded audio file and $30 \mathrm{~cm}$ height box whilst wearing a Polar FS1 heart rate monitor (Polar Electro, Warwick, UK). The participant listened to the audio file instructions and then commenced stepping up and down from the box in time with a metronome beat at a rate of 60 beats per minute (level 1). Each level was two minutes in duration with heart rate and Borg Rating of Perceived Exertion [22] being recorded 5 seconds before the end of each stage. The metronome beat increased by a rate of 20 beats per minute at each stage and the test continued until the participant reached $80 \%$ of their maximum predicted heart rate (220-age) or an $\mathrm{RPE}$ of $\geq 14$. Maximum oxygen uptake $\left(\mathrm{VO}_{2 \max }\right)$ was predicted by plotting a line of best fit between the heart rate data points, projecting the line up to maximum heart rate, and estimating the $\mathrm{VO}_{2 \max }(\mathrm{mL} / \mathrm{kg} / \mathrm{min})$ from the $x$-axis [21].

Hypertension and Metabolic Syndrome Definitions

Hypertension was classified as SBP $\geq 130 \mathrm{mmHg}$ and/or DBP $\geq 80 \mathrm{mmHg}$ [23]. METSYN was classified using the International Diabetes Federation definition [24]. This requires the presence of central obesity (WC $\geq 94 \mathrm{~cm}$ for males and $\geq 80 \mathrm{~cm}$ for females), plus two or more of the following risk factors: raised blood pressure (SBP $\geq 130 \mathrm{mmHg}$, $\mathrm{DBP} \geq 85 \mathrm{mmHg}$ or using blood pressure medication), reduced HDL-C $(<1.03 \mathrm{mmol} / \mathrm{L}$ for men and $<1.29 \mathrm{mmol} / \mathrm{L}$ for women $)$, high triglycerides $(\geq 1.7 \mathrm{mmol} / \mathrm{L}$ or using cholesterol medication), and impaired fasting glucose $(\geq 5.6 \mathrm{mmol} / \mathrm{L})$.

\subsection{Statistical Analysis}

Statistical analysis was conducted using SPSS version 22 (IBM, Armonk, New York, NY, USA). Data is presented as mean \pm SD unless otherwise stated. Where there was missing data, those cases were excluded listwise from the relevant models. Chi-square tests were used to explore the association of job type with the prevalence of hypertension, METSYN, abdominal obesity, low HDL-C, high triglycerides, impaired fasting glucose, and smoking status. The association of job type with stress and physical activity levels was explored using chi-square tests. Differences in cardiometabolic risk markers, anthropometric variables, lung function, handgrip strength, and aerobic fitness were compared between job types using independent samples $t$-tests.

Binary logistic regression using the enter method was employed to evaluate odds ratios (ORs) and 95\% confidence intervals (CI) for having METSYN and hypertension. The following variables were included in the METSYN model: job type, age, sex, length of service, smoking status, operational stress score, organisational stress score, physical activity level, $\mathrm{FEV}_{1}, \mathrm{FVC}, \mathrm{VO}_{2 \mathrm{max}}, \mathrm{GRIPR}$, daily sitting and workplace sitting, SLEEP and AUDIT-C score. The hypertension model additionally included TC, HDL-C, triglycerides, glucose, and BMI. Statistical significance was set at $p \leq 0.05$. Statistical trends in the data were considered apparent when $p>0.05-p<0.10$.

\section{Results}

Descriptive characteristics of the sample are shown in Table 1. There was no significant difference in age between job types but length of service was significantly longer in operational personnel $(p=0.02)$. Across the whole sample, there was a prevalence of $17.2 \%$ for METSYN, $60.3 \%$ for hypertension, 50.0\% for high WC, 27.9\% for low HDL-C, $16.5 \%$ for high triglycerides, and $14.0 \%$ for impaired fasting glucose. The prevalence of hypertension, METSYN, daily smokers, and the individual METSYN risk factors for each 
job type is shown in Table 2. Job type was not significantly associated with any of these variables (Table 2).

Table 1. Descriptive characteristics of the sample $(n=137)$.

\begin{tabular}{cccc}
\hline Variable & Non-Operational $(\boldsymbol{n = 6 0 )}$ & Operational $(\boldsymbol{n}=\mathbf{7 7})$ & Whole Sample \\
\hline Female $(n)$ & 49 & 40 & 89 \\
Male $(n)$ & 11 & 37 & 48 \\
Caucasian $(n)$ & 51 & 70 & 88.3 \\
Non-Caucasian $(n)$ & 9 & 7 & 11.7 \\
Age & $43 \pm 12$ & $43 \pm 9$ & $43 \pm 11$ \\
$\quad$ (years) & $11 \pm 10$ & $15 \pm 8$ & $13 \pm 9$ \\
Length of service & & & \\
(years) & &
\end{tabular}

Table 2. Associations of job type with the prevalence of hypertension, metabolic syndrome, metabolic syndrome risk factors, and daily smoking $(n=137)$.

\begin{tabular}{cccc}
\hline Variable & Non-Operational & Operational & $p$ Value \\
\hline Hypertension $(\%)$ & 60.0 & 60.5 & 0.95 \\
Metabolic syndrome $(\%)$ & 13.6 & 20.0 & 0.34 \\
High waist circumference $(\%)$ & 46.7 & 52.6 & 0.49 \\
Low HDL-C & 23.7 & 31.2 & 0.34 \\
High triglycerides & 13.6 & 18.2 & 0.47 \\
Impaired fasting glucose & 16.9 & 11.7 & 0.38 \\
Daily Smoker $(\%)$ & 8.3 & 5.3 & 0.48
\end{tabular}

Chi-square test used to obtain $p$ values. $n=134$ for Metabolic syndrome. HDL, high-density lipoprotein cholesterol.

Job type was not significantly associated with operational or organisational stress (Table 3). A significant association between job type and physical activity levels was found with a higher proportion of operational personnel engaging in moderate and high levels of physical activity than non-operational personnel (Table 3).

Table 3. Associations of job type with stress and physical activity levels.

\begin{tabular}{|c|c|c|c|c|c|c|c|}
\hline \multirow{2}{*}{ Variable } & \multicolumn{3}{|c|}{ Non-Operational } & \multicolumn{3}{|c|}{ Operational } & \multirow{2}{*}{$p$ Value } \\
\hline & Low & Moderate & High & Low & Moderate & High & \\
\hline Police operational stress score $(\%)^{a}$ & 51.7 & 27.6 & 20.7 & 55.3 & 30.3 & 14.5 & 0.64 \\
\hline Police organisational stress score $(\%)^{b}$ & 48.3 & 33.3 & 18.3 & 45.9 & 28.4 & 25.7 & 0.58 \\
\hline Physical activity level classification (\%) ${ }^{c}$ & 33.3 & 36.7 & 30.0 & 15.8 & 38.2 & 46.1 & 0.04 \\
\hline
\end{tabular}

Chi-square test used to obtain $p$ values. $n=134$ for police operational and organisational stress score, $n=136$ for physical activity level classification. ${ }^{a}$ Police operational stress classification: Low $<2.6$, Moderate 2.7-3.9, High $\geq 4.0$ [16]. ${ }^{\mathrm{b}}$ Police organisational stress classification: Low <2.0, Moderate 2.1-3.4, High $\geq 3.5$ [16]. ${ }^{\mathrm{c}}$ International Physical Activity Questionnaire classification: Low $=$ not meeting any of criteria for Moderate or High, Moderate $=3$ or more days of vigorous intensity activity and/or walking of at least 30 min per day or 5 or more days of moderate intensity activity and/or walking of at least $30 \mathrm{~min}$ per day or 5 or more days of any combination of walking, moderate intensity or vigorous intensity activities achieving a minimum total physical activity of at least $600 \mathrm{MET}$-minutes/week, High = Vigorous intensity activity on at least 3 days achieving a minimum total physical activity of at least 1500 MET-minutes/week or 7 or more days of any combination of walking, moderate intensity or vigorous intensity activities achieving a minimum total physical activity of at least 3000 MET-minutes/week [14].

Operational personnel had significantly higher WC, waist-to-hip ratio, $\mathrm{FEV}_{1}, \mathrm{FVC}$, $\mathrm{VO}_{2 \max }$, and handgrip strength than non-operational personnel. Operational personnel also had significantly lower HDL-C concentrations and engaged in significantly less daily sitting (Table 4). There was a trend for a higher BMI and TC:HDL ratio in operational personnel. There was a trend for higher body fat $\%$ and $\mathrm{FEV}_{1}: \mathrm{FVC}$ ratio in non-operational personnel. 
Table 4. Differences in measures of health, health behaviours, and fitness between operational and non-operational police workers $(n=137)$. Data presented as mean \pm SD.

\begin{tabular}{|c|c|c|c|}
\hline Variable & Non-Operational & Operational & $p$ Value \\
\hline Systolic blood pressure (mmHg) & $122 \pm 14$ & $125 \pm 13$ & 0.21 \\
\hline Diastolic blood pressure (mmHg) & $81 \pm 9$ & $81 \pm 8$ & 0.86 \\
\hline Body fat percentage & $33.5 \pm 8.5$ & $30.8 \pm 9.0$ & 0.08 \\
\hline Waist circumference $(\mathrm{cm})$ & $82.5 \pm 13.5$ & $89.7 \pm 13.3$ & $<0.01$ \\
\hline Waist-to-hip ratio & $0.80 \pm 0.07$ & $0.88 \pm 0.20$ & $<0.01$ \\
\hline $\mathrm{FEV}_{1}(\mathrm{~L})$ & $3.2 \pm 0.6$ & $3.6 \pm 0.8$ & $<0.01$ \\
\hline Forced vital capacity (L) & $3.9 \pm 0.7$ & $4.5 \pm 1.1$ & $<0.01$ \\
\hline $\mathrm{FEV}_{1}: \mathrm{FVC}$ ratio $(\%)$ & $81.6 \pm 5.5$ & $79.7 \pm 5.7$ & 0.06 \\
\hline Maximum oxygen uptake $(\mathrm{mL} / \mathrm{kg} / \mathrm{min})$ & $33.2 \pm 6.4$ & $36.1 \pm 6.7$ & 0.01 \\
\hline Grip strength right hand $(\mathrm{Kg})$ & $27.2 \pm 7.7$ & $36.5 \pm 9.3$ & $<0.01$ \\
\hline Grip strength left hand $(\mathrm{Kg})$ & $25.7 \pm 8.2$ & $33.8 \pm 8.9$ & $<0.01$ \\
\hline Daily sitting (hours/day) & $8.4 \pm 2.8$ & $6.8 \pm 2.8$ & $<0.01$ \\
\hline Workplace sitting (hours/day) & $6.3 \pm 3.0$ & $5.6 \pm 2.6$ & 0.11 \\
\hline Sleep (hours / day) & $6.5 \pm 0.8$ & $6.7 \pm 1.1$ & 0.18 \\
\hline Alcohol use disorder score & $3.8 \pm 2.1$ & $3.5 \pm 2.2$ & 0.45 \\
\hline Total cholesterol (mmol/L) & $5.38 \pm 1.09$ & $5.42 \pm 1.16$ & 0.82 \\
\hline HDL-C $(\mathrm{mmol} / \mathrm{L})$ & $1.57 \pm 0.48$ & $1.41 \pm 0.43$ & 0.05 \\
\hline TC:HDL ratio & $3.73 \pm 1.52$ & $4.24 \pm 1.83$ & 0.08 \\
\hline Triglycerides (mmol/L) & $1.14 \pm 0.63$ & $1.28 \pm 0.78$ & 0.27 \\
\hline Glucose $(\mathrm{mmol} / \mathrm{L})$ & $5.01 \pm 0.70$ & $5.09 \pm 0.46$ & 0.46 \\
\hline Body mass index $\left(\mathrm{kg} / \mathrm{m}^{2}\right)$ & $26.4 \pm 5.4$ & $28.0 \pm 4.4$ & 0.06 \\
\hline
\end{tabular}

Independent samples $t$-tests were used to obtain $p$ values. $\mathrm{FEV}_{1}$, Forced expiratory volume in one second; $\mathrm{FEV}_{1}$ :FVC ratio, Forced expiratory volume in one second:Forced vital capacity ratio; HDL-C, High density lipoprotein cholesterol; TC:HDL ratio, Total cholesterol:High-density lipoprotein cholesterol ratio. Variables with missing data; Maximum oxygen uptake $(n=7)$, HDL-C $(n=7)$, Triglycerides $(n=4)$ and Body fat $\%(n=1)$.

The regression model for hypertension explained $58 \%$ of variance and correctly classified $83 \%$ of cases. Variables contributing significantly to the model were job type, organisational stress, HDL-C, and BMI (Table 5). The odds of hypertension were 0.10 times lower for operational than non-operational personnel, 0.12 times lower for those with moderate organisational stress than those with low organisational stress, 0.16 times lower for each unit increase in HDL, and 1.24 times higher for each unit increase in BMI. There was also a trend for increasing handgrip strength and sleep being associated with higher odds of hypertension.

The regression model for METSYN explained $28 \%$ of variance and correctly classified $86 \%$ of cases. The odds of having METSYN were not significantly associated with any independent variables. There was a trend for lower odds of METSYN with increasing alcohol use disorder scores. 
Table 5. Odds ratios for metabolic syndrome and hypertension according to each predictor variable $(n=121)$.

\begin{tabular}{|c|c|c|c|c|}
\hline \multirow{2}{*}{ Variable } & \multicolumn{2}{|c|}{ Metabolic Syndrome } & \multicolumn{2}{|c|}{ Hypertension } \\
\hline & OR $(95 \% \mathrm{CI})$ & $p$ Value & OR $(95 \%$ CI $)$ & $p$ Value \\
\hline Job type ${ }^{a}$ & $2.38(0.58,9.78)$ & 0.23 & $0.10(0.02,0.51)$ & 0.01 \\
\hline Age (Years) & $1.03(0.94,1.14)$ & 0.50 & $1.03(0.94,1.13)$ & 0.54 \\
\hline Sex ${ }^{b}$ & $2.18(0.29,16.42)$ & 0.45 & $2.71(0.25,29.28)$ & 0.41 \\
\hline Length of service (Years) & $0.99(0.91,1.08)$ & 0.87 & $1.03(0.95,1.12)$ & 0.44 \\
\hline Daily smoker ${ }^{c}$ & $1.37(0.08,23.17)$ & 0.83 & $2.94(0.26,32.75)$ & 0.38 \\
\hline Police operational stress score (Moderate) ${ }^{d}$ & $1.20(0.32,4.55)$ & 0.79 & $1.42(0.33,6.04)$ & 0.64 \\
\hline Police operational stress score (High) ${ }^{d}$ & $2.17(0.36,13.07)$ & 0.40 & $0.41(0.07,2.45)$ & 0.33 \\
\hline Police organisational stress score (Moderate) ${ }^{d}$ & $1.06(0.27,4.11)$ & 0.93 & $0.12(0.03,0.50)$ & $<0.01$ \\
\hline Police organisational stress score (High) $d$ & $1.24(0.25,6.145)$ & 0.79 & $0.54(0.12,2.50)$ & 0.43 \\
\hline Physical activity level classification (Moderate) ${ }^{\mathrm{e}}$ & $0.43(0.10,1.96)$ & 0.28 & $0.58(0.12,2.73)$ & 0.49 \\
\hline Physical activity level classification (High) ${ }^{e}$ & $0.47(0.10,2.27)$ & 0.35 & $0.58(0.10,3.46)$ & 0.55 \\
\hline $\mathrm{FEV}_{1}(\mathrm{~L})$ & $8.25(0.32,216.30)$ & 0.21 & $0.35(0.02,5.66)$ & 0.46 \\
\hline Forced vital capacity $(\mathrm{L})$ & $0.14(0.01,1.45)$ & 0.10 & $1.49(0.19,11.36)$ & 0.70 \\
\hline Maximum oxygen uptake (mL/kg/min) & $0.94(0.82,1.08)$ & 0.12 & $1.01(0.89,1.15)$ & 0.85 \\
\hline Grip strength right hand $(\mathrm{Kg})$ & $1.07(0.98,1.17)$ & 0.37 & $1.11(0.98,1.26)$ & 0.09 \\
\hline Daily sitting (hours/day) & $1.16(0.86,1.57)$ & 0.32 & $1.04(0.78,1.39)$ & 0.80 \\
\hline Workplace sitting (hours/day) & $0.86(0.66,1.12)$ & 0.27 & $0.91(0.69,1.19)$ & 0.49 \\
\hline Sleep (hours / day) & $0.83(0.46,1.50)$ & 0.54 & $1.82(0.95,3.49)$ & 0.07 \\
\hline Alcohol use disorder score & $0.76(0.57,1.02)$ & 0.07 & $1.05(0.78,1.40)$ & 0.76 \\
\hline Total cholesterol $(\mathrm{mmol} / \mathrm{l})$ & - & - & $1.59(0.82,3.08)$ & 0.17 \\
\hline High density Lipoprotein-Cholesterol (mmol/L) & - & - & $0.13(0.03,0.70)$ & 0.02 \\
\hline Triglycerides $(\mathrm{mmol} / \mathrm{L})$ & - & - & $3.29(0.52,20.63)$ & 0.20 \\
\hline Glucose $(\mathrm{mmol} / \mathrm{L})$ & - & - & $0.66(0.20,2.19)$ & 0.50 \\
\hline Body mass index $\left(\mathrm{kg} / \mathrm{m}^{2}\right)$ & - & - & $1.24(1.03,1.48)$ & 0.02 \\
\hline
\end{tabular}

Binary logistic regression using enter method was used to obtain $p$ values. $\mathrm{FEV}_{1}$, Forced expiratory volume in one second. ${ }^{a}$ Non-operational personal used as reference category, ${ }^{\mathrm{b}}$ Females used as reference category, ${ }^{\mathrm{c}}$ Non-smoker used as reference category, ${ }^{\mathrm{d}}$ Low stress scored used as reference category, ${ }^{\mathrm{e}}$ Low physical activity levels used as reference category.

\section{Discussion}

\subsection{Overview of Main Findings}

The main findings of this study were that the high prevalence of hypertension in police personnel was associated with job type, whereas the prevalence of METSYN was not. Specifically, operational personnel had lower odds of hypertension than non-operational. In addition, operational personnel had higher levels of abdominal adiposity and lower HDL$\mathrm{C}$, but had more favourable lung function and handgrip strength profiles, and engaged in more physical activity and less daily sitting.

\subsection{Hypertension}

Both operational and non-operational police had a high prevalence of hypertension (60.5\% and $60.0 \%$ prevalence, respectively) that exceeds the $28 \%$ prevalence seen in the general population in England [25]. Our findings also suggest that hypertension may be more prevalent than findings from the Airwave Health Monitoring Study in the UK where prevalence rates of hypertension were $29.5 \%$ in police personnel [26]. A study using the same Airwave Health Monitoring Study cohort of police employees by Gibson et al. [27]. also reported high levels of elevated blood pressure in males (68.7\%) and females $(33.5 \%)$, which are more aligned with the prevalence in the current study. The increased prevalence found by Gibson et al. [27] can be explained by the use of thresholds to define elevated blood pressure (SBP $\geq 130 \mathrm{mmHg}$ and/or DBP $\geq 85 \mathrm{mmHg}$ ) compared to Elliott et al. [26], who aimed to determine prevalence of hypertension (SBP $\geq 140 \mathrm{mmHg}$ and/or $\mathrm{DBP} \geq 90 \mathrm{mmHg}$ ). The present study extends knowledge in this field by demonstrating that hypertension is highly prevalent in both operational and non-operational police personnel, which had not previously been reported. 
Although the prevalence of hypertension was high in both operational and nonoperational personnel, operational personnel had lower odds of hypertension. This was despite operational personnel having lower HDL-C and a higher abdominal adiposity, which are risk factors for hypertension [28,29]. Operational personnel did possess more favourable grip strength, lung function, cardiorespiratory fitness levels, engaged in higher amounts of physical activity, and also sat less throughout the day than non-operational personnel. These may be protective factors that could explain the lower odds of hypertension in operational personnel [30-34]. However, it should be noted that the prevalence rates of hypertension for non-operational and operational personnel were not different according to the chi-square analysis. This suggests that other factors that were considered statistically significant in the logistic regression model are important when evaluating the likelihood of having hypertension, which is indeed supported by the findings.

Police in operational and non-operational roles engage in large amounts of desk work [4]. This was supported by findings in the present study in which operational and non-operational personnel engaged in 5.6 and $6.3 \mathrm{~h}$ per day of workplace sitting, respectively. However, daily and workplace sitting time were not associated with the presence of hypertension. On the contrary, previous prospective evidence in the general population $(n=11,837)$ found that higher total daily sedentary behaviour was associated with an increased risk of hypertension [34]. The smaller sample size and cross-sectional design of the present study could explain the disparity in findings compared to previous research. Prospective studies in larger samples of police personnel are thus needed to confirm whether sedentary behaviour and other demographic, health, and behavioural factors are associated with the high prevalence of hypertension in the police.

Moderate levels of organisational stress were associated with lower odds of hypertension compared with low organisational stress levels. This is in contrast with a previous systematic review that reported stress was frequently associated with hypertension in police officers [35]. It is not clear why moderate levels of stress could be associated with lower odds of hypertension. Operational and non-operational personnel had similar stress scores so job type may not be an important factor in explaining this phenomenon. Further research is thus required to aid in understanding the health effects of stress in the police.

\subsection{Metabolic Syndrome}

There was a high prevalence of METSYN in non-operational and operational personnel in the present study (13.6\% and 20.0\%, respectively). This is similar to the general European population with prevalence rates of $10-30 \%$ reported [36]. The present findings are also similar to the $16.8 \%$ prevalence reported in police officers in India [37]. Previous literature has indicated that greater METSYN prevalence (36.4\%) exists in police officers compared with the present study [38]. In the study by Leischik et al. [38], it is unclear whether, like in the current study, a high WC was a mandatory risk factor in their definition of METSYN. If it was not, then this would at least partly explain the higher prevalence of METSYN in their study. Regardless, METSYN prevalence in this occupational group is high and intervention strategies to improve cardiometabolic health are thus warranted.

None of the variables evaluated in this study were significantly associated with METSYN. There was a trend for lower odds of METSYN with increasing alcohol use disorder scores. This is in contrast to previous research that reported higher alcohol intake to be associated with an increased risk of METSYN in the general population [39] and in police officers in China [40]. Although the questionnaires used to measure alcohol intake varied between studies, it is unlikely that this alone would explain these disparate findings. Instead, it may be possible that police personnel with higher alcohol use disorder scores may engage in other healthy behaviours that protect them against abnormal cardiometabolic health.

It has been suggested that irregular working hours, shift patterns, and diet may be contributing factors to an increased likelihood of METSYN in the police [41,42]. These were not assessed in the present study and should be considered in future research to 
help elucidate possible links with alcohol intake in relation to the risk of METSYN in this occupational group. Furthermore, previous studies in the police have reported associations between a number of the variables evaluated in this study and METSYN. For instance, age, BMI, and smoking were significantly associated with METSYN in Indian police officers [43]. These contrasting findings may be due to differences in societal health behaviours between India and the UK. It is recommended that research is conducted to identify the predictors of METSYN in the police and how these may differ across different job types and in different environmental contexts.

\subsection{Physiological, Psychological, and Behavioural Profiles of Operational and Non-Operational Police}

Our findings revealed an adverse cardiometabolic health profile in operational compared to non-operational personnel demonstrated by lower HDL-C, higher WC and WHR, and a trend for higher BMI and TC:HDL ratio. To the authors' knowledge, no previous research has compared cardiometabolic risk between different job types in the police. Previous evidence has consistently documented that police officers have an increased cardiometabolic risk than the general population [7]. This increased physiological risk existed despite operational personnel having significantly better handgrip strength, lung function, higher physical activity levels, and lower daily sitting, which have been favourably associated with cardiometabolic health [30-34]. This supports the need for occupational health interventions to reduce the risk of cardiometabolic disease in the police, especially those in operational jobs.

This study's novel findings also demonstrate that workplace sitting time is similar between job types in the police, which shows that operational personnel conduct a significant amount of their work while seated. This study did not explore how or where the participants engaged in sitting, such as whether it was predominantly sitting at a desk, while patrolling in police vehicles or conducting tasks like interviews and taking statements. This should be addressed in future research to help inform intervention development and occupational health policies.

\subsection{Strengths and Limitations}

The main strength of this study includes the comprehensive evaluation of a multitude of physiological, psychological, behavioural, and demographic variables in the context of their differences between operational and non-operational police personnel and their association with hypertension and METSYN. The study is limited by not including some factors that could be important in explaining differences in health profiles between operational and non-operational personnel and could have a role in the risk of hypertension and METSYN. This may include shift work, family history of hypertension and METSYN, and diet. These factors should be considered in future research. The study is also limited due to it being set within a specific occupational group and the findings may thus not generalise to other occupation groups or the general population.

\section{Conclusions}

This study suggests that there is a high prevalence of hypertension and METSYN in both operational and non-operational police personnel. It is therefore recommended that interventions to reduce the risk of hypertension and METSYN in the police target both of these job types to reduce the risk of cardiometabolic disease. It should be acknowledged that several cardiometabolic risk markers were higher in operational police, yet an operational job type was associated with lower odds of hypertension. Concerted efforts may thus be needed for both occupational groups.

Author Contributions: All authors were involved in the conceptualisation of the project. A.C.S.M., J.C.R., and A.M.C. established the link with the police. J.D.Y., J.C.R., and J.W.F.A. established the research design. A.M.C. compiled health behaviour questionnaires. J.D.Y. collected the data. J.D.Y., J.W.F.A., and D.P.B. were involved in the data analysis and interpretation. J.D.Y. and D.P.B. developed 
the manuscript. All authors were involved in editing the manuscript. J.C.R. supervised the project. All authors have read and agreed to the published version of the manuscript.

Funding: This research was funded through support from the Office of the Police and Crime Commissioner at Bedfordshire Police (grant number NUT14618).

Institutional Review Board Statement: The study was conducted according to the guidelines of the Declaration of Helsinki, and approved by the Institutional Review Board (or Ethics Committee) of the University of Bedfordshire (2018ISPAR012).

Informed Consent Statement: Informed consent for participation and publication of results was obtained from all subjects involved in the study.

Data Availability Statement: The unidentified data presented in this study is available on reasonable request from the corresponding author.

Acknowledgments: This study was supported by the Office of the Police and Crime Commissioner at a territory Police organisation in the UK. This study formed part of the thesis completed by J.Y. whilst undertaking a Master of Science by Research degree. The Master of Science by Research undertaken by J.Y. was a funded studentship opportunity provided by a territory Police organisation in the UK in collaboration with the Institute for Sport and Physical Activity Research at the University of Bedfordshire.

Conflicts of Interest: The authors declare no conflict of interest.

\section{References}

1. Home Office. Police Workforce, England and Wales, as at 30 September 2020 National Statistics; Home Office: London, UK, 2021.

2. Elliott-Davies, M.; Donnelly, J.; Boag-Munroe, F.; Van Mechelen, D. 'Getting a battering' The perceived impact of demand and capacity imbalance within the Police Service of England and Wales: A qualitative review. Police J. Theory Pract. Princ. 2016, 89, 93-116. [CrossRef]

3. Houdmont, J.; Elliott-Davies, M. Police Federation of England and Wales Officer Demand, Capacity, and Welfare Survey: Initial Report-Descriptive Results; Police Federation of England and Wales: Leatherhead, UK, 2016.

4. Dick, G.; Metcalfe, B. Managerial factors and organisational commitment-A comparative study of police officers and civilian staff. Int. J. Public Sect. Manag. 2001, 14, 111-128. [CrossRef]

5. Kales, S.N.; Tsismenakis, A.J.; Zhang, C.; Soteriades, E.S. Blood pressure in firefighters, police officers, and other emergency responders. Am. J. Hypertens. 2009, 22, 11-20. [CrossRef]

6. Zimmerman, F.H. Cardiovascular disease and risk factors in law enforcement personnel: A comprehensive review. Cardiol. Rev. 2012, 20, 159-166. [CrossRef]

7. Lee, P.H.; Wong, F.K. The association between time spent in sedentary behaviors and blood pressure: A systematic review and meta-analysis. Sports Med. 2015, 45, 867-880. [CrossRef] [PubMed]

8. Edwardson, C.L.; Gorely, T.; Davies, M.J.; Gray, L.J.; Khunti, K.; Wilmot, E.G.; Yates, T.; Biddle, S.J. Association of sedentary behaviour with metabolic syndrome: A meta-analysis. PLoS ONE 2012, 7, 34916. [CrossRef] [PubMed]

9. Bailey, D.P.; Hewson, D.J.; Champion, R.B.; Sayegh, S.M. Sitting Time and Risk of Cardiovascular Disease and Diabetes: A Systematic Review and Meta-Analysis. Am. J. Prev. Med. 2019, 57, 408-416. [CrossRef] [PubMed]

10. Loveday, B. Police management and workforce reform in a period of austerity. In Police Services: Leadership and Management Perspectives; Wankhade, P., Weir, D., Eds.; Springer: Cham, Switzerland, 2015; pp. 115-127.

11. Thornton, G.; Harper, R.H. Detectives or Clerks? An Examination of the Work of Detectives; Technical Report; Rank Xerox Research Centre Cambridge Laboratory: Cambridge, UK, 1991.

12. Marshall, A.L.; Miller, Y.D.; Burton, N.W.; Brown, W.J. Measuring total and domain-specific sitting: A study of reliability and validity. Med. Sci. Sports Exerc. 2010, 42, 1094-1102. [CrossRef]

13. Craig, C.L.; Marshall, A.L.; Sjöström, M.; Bauman, A.E.; Booth, M.L.; Ainsworth, B.E.; Pratt, M.; Ekelund, U.; Yngve, A.; Sallis, J.F.; et al. International physical activity questionnaire: 12-country reliability and validity. Med. Sci. Sports Exerc. 2003, 35, 1381-1395. [CrossRef]

14. Meneses-Gaya, C.; Zuardi, A.W.; Loureiro, S.R.; Hallak, J.E.C.; Trzesniak, C.; De Azevedo-Marques, J.M.; Machado-De-Sousa, J.P.; Chagas, M.H.N.; Souza, R.M.; Crippa, J.A.S. Is the Full Version of the AUDIT Really Necessary? Study of the Validity and Internal Construct of Its Abbreviated Versions. Alcohol. Clin. Exp. Res. 2010, 34, 1417-1424. [CrossRef]

15. McCreary, D.R.; Thompson, M.M. Development of two reliable and valid measures of stressors in policing: The operational and organisational police stress questionnaires. Int. J. Stress Manag. 2006, 13, 494-518. [CrossRef]

16. McCreary, D.R.; Fong, I.; Groll, D.L. Measuring policing stress meaningfully: Establishing norms and cut-off values for the Operational and Organizational Police Stress Questionnaires. Police Pract. Res. 2017, 18, 612-623. [CrossRef] 
17. Dalton, M.; Cameron, A.J.; Zimmet, P.Z.; Shaw, J.E.; Jolley, D.; Dunstan, D.W.; Welborn, T.A.; AusDiab Steering Committee. Waist circumference, waist-hip ratio and body mass index and their correlation with cardiovascular disease risk factors in Australian adults. J. Intern. Med. 2003, 254, 555-563. [CrossRef]

18. Koegelenberg, C.F.N.; Swart, F.; Irusen, E.M. Guideline for office spirometry in adults. S. Afr. Med. J. 2012, 103, 52-61. [CrossRef]

19. Fess, E.E. Grip Strength, 2nd ed.; American Society of Hand Therapists: Chicago, CA, USA, 1992.

20. Tsang, R.C. Reference Values for 6-Minute Walk Test and Hand-Grip Strength in Healthy Hong Kong Chinese Adults. Hong Kong Physiother. J. 2005, 23, 6-12. [CrossRef]

21. Sykes, K.; Roberts, A. The Chester step test-A simple yet effective tool for the prediction of aerobic capacity. Physio-Therapy 2004, 90, 183-188. [CrossRef]

22. Borg, G.A. Psychophysical bases of perceived exertion. Med. Sci. Sports Exerc. 1982, 14, 377-381. [CrossRef] [PubMed]

23. Carey, R.M.; Whelton, P.K. Prevention, detection, evaluation, and management of high blood pressure in adults: Synopsis of the 2017 American College of Cardiology/American Heart Association hypertension guideline. Ann. Intern. Med. 2018, 168, 351-358. [CrossRef] [PubMed]

24. Alberti, K.G.M.M.; Zimmet, P.; Shaw, J. Metabolic syndrome-a new world-wide definition. A Consensus Statement from the International Diabetes Federation. Diabet. Med. 2006, 23, 469-480. [CrossRef]

25. Lifestyles Team, NHS Digital. Health Survey for England 2018; Lifestyles Team, NHS Digital: London, UK, 2018.

26. Elliott, P.; Vergnaud, A.-C.; Singh, D.; Neasham, D.; Spear, J.; Heard, A. The Airwave Health Monitoring Study of police officers and staff in Great Britain: Rationale, design and methods. Environ. Res. 2014, 134, 280-285. [CrossRef] [PubMed]

27. Gibson, R.; Eriksen, R.; Singh, D.; Vergnaud, A.C.; Heard, A.; Chan, Q.; Elliott, P.; Frost, G. A cross-sectional investigation into the occupational and socio-demographic characteristics of British police force employees reporting a dietary pattern associated with cardiometabolic risk: Findings from the Airwave Health Monitoring Study. Eur. J. Nutr. 2017, 57, 1-14. [CrossRef] [PubMed]

28. Islam, S.; Choudhury, K.N.; Mainuddin, A.; Wahiduzzaman, M. Serum lipid profile and its association with hypertension in Bangladesh. Vasc. Health Risk Manag. 2014, 10, 327. [CrossRef] [PubMed]

29. Taylor, S.A.; Hergenroeder, A.C. Waist circumference predicts increased cardiometabolic risk in normal weight adolescent males. Pediatr. Obes. 2011, 6 (Suppl. 3), 307-311. [CrossRef] [PubMed]

30. Hao, G.; Chen, H.; Ying, Y.; Wu, M.; Yang, G.; Jing, C. The Relative Handgrip Strength and Risk of Cardiometabolic Disorders: A Prospective Study. Front. Physiol. 2020, 11, 719. [CrossRef]

31. Wu, Y.; Vollmer, W.M.; Buist, A.S.; Tsai, R.; Cen, R.; Wu, X.; Chen, P.; Lai, Y.; Guo, C.; Mai, J.; et al. Relationship between lung function and blood pressure in Chinese men and women of Beijing and Guangzhou. Int. J. Epidemiol. 1998, 27, 49-56. [CrossRef]

32. Rankinen, T.; Church, T.S.; Rice, T.; Bouchard, C.; Blair, S.N. Cardiorespiratory fitness, BMI, and risk of hypertension: The HYPGENE study. Med. Sci. Sports Exerc. 2007, 39, 1687. [CrossRef]

33. Huai, P.; Xun, H.; Reilly, K.H.; Wang, Y.; Ma, W.; Xi, B. Physical activity and risk of hypertension: A meta-analysis of prospective cohort studies. Hypertension 2013, 62, 1021-1026. [CrossRef]

34. Bes-Rastrollo, M.; Martínez, J.A.; Martinez-Gonzalez, M.A.; Ebrahim, S.; Beunza, J.J.; Núñez, J.; Alonso, Á. Sedentary Behaviors and the Risk of Incident Hypertension: The SUN Cohort. Am. J. Hypertens. 2007, 20, 1156-1162. [CrossRef]

35. Magnavita, N.; Capitanelli, I.; Garbarino, S.; Pira, E. Work-related stress as a cardiovascular risk factor in police officers: A systematic review of evidence. Int. Arch. Occup. Environ. Health 2018, 91, 377-389. [CrossRef]

36. Van Vliet-Ostaptchouk, J.V.; Nuotio, M.L.; Slagter, S.N.; Doiron, D.; Fischer, K.; Foco, L.; Gaye, A.; Gögele, M.; Heier, M.; Hiekkalinna, T.; et al. The prevalence of metabolic syndrome and metabolically healthy obesity in Europe: A collaborative analysis of ten large cohort studies. BMC Endocr. Disord. 2014, 14, 9. [CrossRef]

37. Thayyil, J.; Jayakrishnan, T.T.; Raja, M.; Cherumanalil, J.M. Metabolic syndrome and other cardiovascular risk factors among police officers. N. Am. J. Med. Sci. 2012, 4, 630. [CrossRef] [PubMed]

38. Leischik, R.; Foshag, P.; Strauß, M.; Littwitz, H.; Garg, P.; Dworrak, B.; Horlitz, M. Aerobic capacity, physical activity and metabolic risk factors in firefighters com-pared with police officers and sedentary clerks. PLoS ONE 2015, 10, 0133113.

39. Baik, I.; Shin, C. Prospective study of alcohol consumption and metabolic syndrome. Am. J. Clin. Nutr. 2008, 87, 1455-1463. [CrossRef]

40. Zhang, J.; Liu, Q.; Long, S.; Guo, C.; Tan, H. Prevalence of metabolic syndrome and its risk factors among 10,348 police officers in a large city of China: A cross-sectional study. Medicine 2019, 98, e17306. [CrossRef] [PubMed]

41. Violanti, J.M.; Burchfiel, C.M.; Hartley, T.A.; Mnatsakanova, A.; Fekedulegn, D.; Andrew, M.E.; Charles, L.E.; Vila, B.J. Atypical Work Hours and Metabolic Syndrome Among Police Officers. Arch. Environ. Occup. Health 2009, 64, 194-201. [CrossRef] [PubMed]

42. Wirth, M.D.; Burch, J.; Shivappa, N.; Violanti, J.M.; Burchfiel, C.M.; Fekedulegn, D.; Andrew, M.E.; Hartley, T.A.; Miller, D.B.; Mnatsakanova, A.; et al. Association of a Dietary Inflammatory Index With Inflammatory Indices and Metabolic Syndrome Among Police Officers. J. Occup. Environ. Med. 2014, 56, 986-989. [CrossRef] [PubMed]

43. Tharkar, S.; Kumpatla, S.; Muthukumaran, P.; Viswanathan, V. High prevalence of metabolic syndrome and cardiovascular risk among police personnel compared to general population in India. J. Assoc. Physicians India 2008, 56, 19263681. 